\title{
Effects of Physical Activity and Psychological Modification-Based Intervention on Physical Fitness, Physical Activity and Its Related Psychological Variables in Female Adolescents
}

\author{
YoungHo Kim (D) and InKyoung Park *(D)
}

check for

updates

Citation: Kim, Y.; Park, I. Effects of Physical Activity and Psychological Modification-Based Intervention on Physical Fitness, Physical Activity and Its Related Psychological Variables in Female Adolescents. Int. J. Environ. Res. Public Health 2021, 18, 9510. https://doi.org/10.3390/ ijerph18189510

Academic Editor: Wi-Young So

Received: 31 July 2021

Accepted: 5 September 2021

Published: 9 September 2021

Publisher's Note: MDPI stays neutral with regard to jurisdictional claims in published maps and institutional affiliations.

Copyright: (C) 2021 by the authors Licensee MDPI, Basel, Switzerland. This article is an open access article distributed under the terms and conditions of the Creative Commons Attribution (CC BY) license (https:/ / creativecommons.org/licenses/by/ $4.0 /)$.
Department of Sport Science, Seoul National University of Science and Technology, Seoul 01811, Korea; yk01@seoultech.ac.kr

* Correspondence: pik77812@nate.com; Tel.: +82-2-970-6369

\begin{abstract}
Background: The current study investigated the effects of an intervention incorporating physical activity and psychological modification strategy on physical fitness, physical activity levels, and psychological variables related to physical activity in female adolescents. Methods: Sixty female adolescents were recruited from $\mathrm{H}$ Middle School. Among them, 30 females (Mage $=14.35$ years) were randomly assigned to the experimental group and the rest of 30 to the control group (Mage = 14.47 years) and voluntarily participated in the 12-week intervention. Results: The results indicated that the physical activity stage of female adolescents in the experimental group significantly increased over the 12-week intervention. The results revealed that all of psychological variables in the experimental group significantly improved over the intervention, while participants in the experimental group showed significantly higher scores on most of psychological variables, except cons, than those in the control group after the intervention. Moreover, most of physical fitness components in the experimental group significantly increased over the intervention. Conclusions: The current study confirmed that the physical activity-related psychological intervention was feasible for improving physical and psychological health among female adolescents.
\end{abstract}

Keywords: female adolescent; psychological strategy; transtheoretical model; physical activity; physical fitness; tabata exercise

\section{Introduction}

It is broadly documented that regular physical activity is an important health-related behavior to improve adolescents' physical and psychological health and protect them from various diseases [1]. Also, regular participation in physical activity during adolescence positively affects satisfaction in school and daily life, further preparing them for adulthood and laying the foundation for lifelong physical activity. Despite the various health benefits of regular physical activity, a large number of adolescents around the world have failed to engage in regular physical activity [2,3]. According to a recent survey by the Ministry of Health and Welfare [4], only $32 \%$ of Korean adolescents engaged in high-intensity physical activity for at least 3 days a week, and the rate among female adolescents (18\%) was found to be significantly lower than among male peers (44.8\%). Furthermore, the World Health Organization [3] surveyed adolescents' physical activity rate and reported that their physical activity rate is very low and might have serious effects on their future health status (i.e., America: male 36\%, female 19.5\%; England: male 25.3\%, female 14.6\%; Australia: male $23.2 \%$, female $18.6 \%$ ). Thus, the adolescent participation rate in physical activity is very low both at home and abroad, which can be a leading cause of deaths due to diabetes and cardiovascular diseases in adulthood as well as negative effects such as an increased likelihood of mental disorders like anxiety and depression [5]. From previous large-scale Korean and international statistics, we should notice that the high rates of 
physical inactivity in female adolescents are globally reported. Along with the high rates of physical inactivity, adolescents' physical fitness such as muscle strength, muscle endurance, flexibility, power, and cardiovascular endurance, consistently declined [6].

In this regard, it is unclear that why many female adolescents are physically inactive. This primary question can be identified to apply a conceptual framework rooting in the social cognitive theory. Additionally, practical efforts should be directed towards cognitive and behavioral strategies based on psychosocial theories for changing and supporting physical activity initiation and/or maintaining among female adolescents [7]. The transtheoretical model (TTM) is a contemporary psychological paradigm that seeks to understand the adoption and maintenance of health behaviors including physical activity [8]. The TTM indicates that physical activity change happens in a variety of stages over time and that the causes of change involve the cognitive and behavioral processes that individuals participate in at the different stages of change. Moreover, as people progress through the stages of physical activity, they should typically experience increased self-efficacy and pros and decreased cons [9].

For more than a decade, many studies across a wide range of populations and settings have shown that there is a significant relationship between physical activity and the TTM constructs [10]. These survey studies can provide valuable findings for the promotion of physical activity among adolescents. Given the significance between psychological attributes and physical activity in adolescents, longitudinal intervention research has focused on increasing physical activity and its linked psychological variables are needed in female adolescents.

In behavioral medicine, recent studies have indicated that the TTM-based comprehensive intervention integrating physical activity and psychological modification strategies is broadly recognized as an effective modality for not only improving physical activity in adolescents, but also in realizing positive changes on the psychological variables linked to physical activity [11,12]. Some studies have indicated that the interventions based on the TTM are effective on promoting physical activity and positively changing psychological variables in various age groups [12,13]. Recently, Jeong and colleagues (2020) applied the intervention combining physical fitness training and cognitive modification strategies for 16 weeks to 120 female adolescents. The results indicated that physical fitness (i.e., power, muscle strength and endurance, flexibility, and cardiovascular endurance), as well as psychological variables such as self-efficacy and perceived benefits, and motivation are significantly improved after the intervention [14].

In spite of the critical effects of the intervention in promoting physical activity and positively changing psychological constructs associated with physical activity, most studies have been conducted in western societies; even research combining psychological strategies and physical activity is lacking in South Korea. The purpose of the current study was to investigate the effects of the intervention integrating psychological modification strategy and physical activity on physical activity, physical fitness, and psychological variables in female adolescents.

\section{Materials and Methods}

\subsection{Participants}

Before recruiting the study participant, G*Power analysis was carried out to identify the proper sample size and the magnitude of effect size. From this test, at least 54 participants with an anticipated statistical power of 0.95 , a $\alpha$-error probability of 0.05 , and an effect size of 0.25 were required for this study. Based on calculating sample size, a total of 60 students were purposefully recruited from $\mathrm{H}$ junior high school, located in the Nowon-gu district, Seoul. Among them, 30 females randomly assigned to the experimental group and the rest of 30 to the control group. The study was conducted according to the guidelines of the Declaration of Helsinki and approved by the institutional review board of Seoul National University of Science and Technology (2020-0565). Table 1 illustrates the characteristics of the participants. 
Table 1. Study participants' characteristics at baseline.

\begin{tabular}{lllll}
\hline Variables & Experimental Group $(\boldsymbol{n}=\mathbf{3 0})$ & Control Group $(\boldsymbol{n = 3 0 )}$ & $\boldsymbol{t}$ & $\boldsymbol{p}$ \\
\hline Age $(\mathrm{yr})$ & $14.35 \pm 0.73$ & $14.47 \pm 0.68$ & 0.27 & 0.59 \\
Height $(\mathrm{cm})$ & $160.75 \pm 5.38$ & $158.55 \pm 5.84$ & 1.51 & 0.14 \\
Weight $(\mathrm{kg})$ & $52.79 \pm 9.27$ & $52.08 \pm 7.77$ & 0.32 & 0.75 \\
BMI $\left(\mathrm{kg} / \mathrm{m}^{2}\right)$ & $20.39 \pm 3.2$ & $20.71 \pm 2.88$ & 0.41 & 0.68 \\
\hline
\end{tabular}

$\mathrm{BMI}=$ body mass index,$t=\mathrm{t}$-value, $p=$ practical significance.

\subsection{Measures}

\subsubsection{Physical Fitness}

In order to evaluate the participants' physical fitness, the Physical Activity Promotion System (PAPS) developed by Korean government was applied for the study. The PAPS is a mandatory evaluation program performed once a year on all elementary, middle, and high school students in South Korea. In PAPS, physical fitness consists of five components (i.e., power, muscle strength and endurance, flexibility, cardiovascular endurance) [14]. The current study measured the essential PAPS evaluation items: $50 \mathrm{~m}$ run for power, sit-up for muscular strength and endurance), sitting trunk flexion for flexibility, and shuttle run for cardiovascular endurance [15].

\subsubsection{Stage of Physical Activity}

To measure the participants' physical activity stages, the stage of change scale for physical activity [16] translated into Korean and used [17]. This questionnaire comprises indicators of five stages for an individual's level of physical activity (i.e., precontemplation, contemplation, preparation, action, and maintenance). The participants were asked to choose one of the five stages that they thought was consistent with their intention to participate in regular physical activity and their actual physical activity level. According to Kim [17], the reliability of the questionnaire was 0.85 , and the internal validity with the LTEQ was 0.81 .

\subsubsection{Physical Activity Level}

In order to measure the amount of physical activity, the leisure time exercise questionnaire (LTEQ) [18] was translated into Korean and applied for this study [19]. In this study, divided into high-intensity, moderate-intensity, and low-intensity categories, the study participants were asked to report how many times during a typical week took part in strenuous (e.g., running, vigorous cycling), moderate (e.g., fast walking, easy swim), and mild (e.g., yoga, golf) physical activity for more than $15 \mathrm{~min}$. The exercise score was multiplied and summed by each intensity level to obtain the total metabolic equivalent $(\mathrm{MET})$ value $[($ strenuous $\times 9)+($ moderate $\times 5)+($ mild $\times 3)]$. The construct validity of the questionnaire was verified by correlation with the accelerometer (Spearman's $\rho=0.77$ ), and the reliability was shown by Cronbach's $\alpha=0.82$ [19].

\subsubsection{Psychological Variables}

The psychometric instruments applied in the current study, were originally developed in English and translated into Korean based on the methodology outlined by Banvile, Desrosiers, and Genet-Volet (2000) [20]. The full translation and validation processes have been described elsewhere [21,22].

To measure the participants' confidence for doing physical activity, the exercise selfefficacy questionnaire [23] was translated and used to the study [24]. In the questionnaire, the study participants answered their confidence levels to participate in physical activity regularly under the various circumstances on a 5-point Likert scale from" not confident at all (1)" to "very confident (5)". The test-retest reliability of the Korean questionnaire was 0.89.

To assess perceived benefits and barriers toward physical activity, the decisional balance scale for Exercise [25] was translated and applied for the study [19]. The scale consists of the two sub-scales (pros and cons with five items each). Study participants 
indicated their perceived level towards what is described in each question on a 5-point Likert scale ranging from "not at all important (1) to "very much important (5)". The test-retest reliability of the Korean questionnaire was 0.91 for pros and 0.89 for cons.

In order to measure participants' behavioral and cognitive strategies for physical activity, the processes of change scale were translated and applied in the study [26]. By using the 5-point Likert scale, students were asked to answer from "never (1)" to "repeatedly (5)". In this study, cognitive processes and behavioral processes were influenced by the second-order factors. The five components in cognitive processes are dramatic relief, consciousness-raising, environmental re-evaluation, self-re-evaluation, and social liberation, whereas five components in behavioral are counter conditioning, helping the relationship, self-liberation, reinforcement management, and stimulus control. The internal reliabilities of the Korean version were 0.84 for cognitive processes of change and 0.87 for behavioral processes of change [27].

\subsection{Intervention}

During the 12-week intervention, the study participants in the experimental group were received the Tabata exercise program and psychological modification strategy, while those in the control group read a book freely for 40 min under the supervision of a coinvestigator without any experimental treatment. The intervention consists of a Tabata exercise and psychological modification strategy that aims at increasing physical activity and physical fitness and improving psychological constructs over 12 weeks (Table 2).

The Tabata exercise program used in the study consists of high-intensity interval training (HIIT) regimen which is generally a form of interval training alternating short periods of intense anaerobic exercise with less intense recovery periods, until the participant is too exhausted to continue [28]. In order to motivate the participants to actively engage, a standardized 10-min warm-up consisting of $5 \mathrm{~min}$ of slow jogging followed by $5 \mathrm{~min}$ of stretching of major muscle groups at first and then the Tabata exercise were performed. The Tabata exercise program was divided into three sessions with a total $14 \mathrm{~min}$ (each lasting $4 \mathrm{~min}$ ). Each session based on the Tabata protocol (20 s work $/ 10 \mathrm{~s}$ rest) consisted of 8 cycles of two exercises. Each cycle started with a maximum intensity exercise lasting for $20 \mathrm{~s}$, in which the participant was motivated to perform as many repetitions as possible of a given exercise involving large muscle groups of the entire body which was followed a 10 s-active rest in the form of a low-intensity exercise. The cycles were repeated without any rests between them [29]. After the Tabata training, the final part of the training including flexibility and relaxation exercises was performed for $16 \mathrm{~min}$ [30].

The psychological modification strategy was based on the materials applied in previous studies [31,32]. The TTM constructs such as self-efficacy, pros, cons, and cognitive and behavioral processes of change, were applied for the motivational and behavioral modification strategies to promote physical activity and physical fitness and positively change psychological variable in female adolescents. At the initial stage, the intervention was aimed at raising accurate awareness of the significance of physical activity and physical fitness. The intermediate stage was emphasized to apply practical techniques to enhancing self-efficacy and social support associated with regular physical activity. The final stage of the intervention was focused on stressing cognitive and behavioral reinforcement techniques for the participants to sustain physical fitness and to promote physical activity participation $[13,32]$. 
Table 2. Physical activity and psychological modification-based intervention.

\begin{tabular}{|c|c|c|c|}
\hline \multirow{2}{*}{ Week } & \multirow{2}{*}{$\begin{array}{l}\text { Physical Activity } \\
\text { (One a Week) } \\
\text { Tabata Exercise }\end{array}$} & \multicolumn{2}{|c|}{ Psychological Modification Strategy (2 Times/Week) } \\
\hline & & Topic & Strategy \\
\hline 1 & 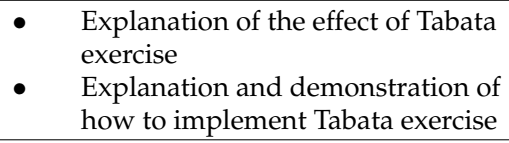 & $\begin{array}{l}\text { - Understanding of physical } \\
\text { activity } \\
\text { - Goal setting }\end{array}$ & $\begin{array}{ll}\text { - } & \text { Introduction of psychological strategy } \\
\text { - } & \text { Awareness of physical inactivity-related } \\
& \text { problems } \\
\text { - } & \text { Setting the target physical activity amount }\end{array}$ \\
\hline 2 & $\begin{array}{ll} & \text { Warm-up }(10 \mathrm{~min}) \\
- & \text { Streching }(6 \mathrm{~min}) \\
- & \text { Tabata exercise }(14 \mathrm{~min}) \\
& 3 \text { sessions } / 4 \text { min. per session }\end{array}$ & $\begin{array}{l}\text { - Identification of current } \\
\text { level }\end{array}$ & $\begin{array}{ll} & \text { Physical activity test (Mets score) } \\
\text { - } & \text { Physical fitness test } \\
\text { - } & \text { Self-efficacy test } \\
& \text { Perceived benefits and barriers test } \\
\end{array}$ \\
\hline 3 & & 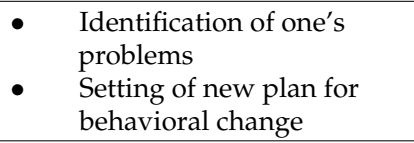 & $\begin{array}{ll}\text { - } & \text { Finding one's reasons for not doing physical } \\
& \text { activity } \\
\text { - } & \text { Discussing one's lifestyle } \\
\text { - } & \text { Setting an achievable physical activity plan }\end{array}$ \\
\hline 4 & & - $\quad$ Physical activity & $\begin{array}{l}\text { - Understanding the importance and effect of } \\
\text { physical activity } \\
\text { - Understanding the significance of physical } \\
\text { - } \quad \text { Ditness training } \\
\text { Discussion one's physical activity habits }\end{array}$ \\
\hline $5-6$ & & - $\quad$ Self-efficacy & $\begin{array}{l}\text { - Understanding the meaning and scope of } \\
\text { physical activity } \\
\text { Identifying the relationship between } \\
\text { self-efficacy and physical activity } \\
\text { Enhancing confidence for promoting } \\
\text { physical activity }\end{array}$ \\
\hline $7-8$ & & $\begin{array}{ll}-\quad \text { Motivation } \\
\text { - } & \text { Perceived benefits and } \\
& \text { barriers }\end{array}$ & $\begin{array}{l}\text { - Understanding the importance of motivation } \\
\text { and perception toward physical activity } \\
\text { Recognizing the benefits and barriers of } \\
\text { physical activity } \\
\text { - Exploring the way to enhance motivation } \\
\text { and perceived benefits }\end{array}$ \\
\hline 9 & & - $\quad$ Social support & $\begin{array}{l}\text { - Understanding the meaning and resources of } \\
\text { social sup-port } \\
\text { - } \quad \text { Asking support from friends and families }\end{array}$ \\
\hline $10-11$ & & - $\quad$ Awareness change & $\begin{array}{l}\text { - Sharing one's thought and experiences about } \\
\text { obesity and physical activity with others } \\
\text { Replacing negative factors for physical } \\
\text { activity with positive ones }\end{array}$ \\
\hline 12 & & $\begin{array}{l}\text { - } \quad \text { Setting new goal for } \\
\text { physical activity }\end{array}$ & $\begin{array}{l}\text { - Identifying the attainment of one's goal and } \\
\text { - } \quad \text { Tewarding it } \\
\text { psychological factors } \\
\text { - Setting new physical activity goal for } \\
\text { maintaining active lifestyle }\end{array}$ \\
\hline
\end{tabular}

\subsection{Data Analysis}

Descriptive data (e.g., mean, standard deviation, kurtosis, and skewness) were analyzed to demonstrate the demographic characteristics of the study participants. A McNemar chi-square $\left(\chi^{2}\right)$ test was performed to test differences in the distribution of the physical activity stages between the experimental group and the control group over 12-week intervention. Two-way repeated-measure ANOVA was conducted to examine differences in physical activity, physical fitness, and psychological constructs between the experimental group and control group over the intervention. All statistical analyses were performed using SPSS Win 26.0 (IBM Corp., Armonk, NY, USA).

\section{Results}

\subsection{Changes in the Stage of Physical Activity}

Table 3 shows the stage transitions of study participants in both experimental and control groups over the 12-week intervention. There is no difference in the stage distributions of physical activity between the experimental and control groups at baseline. In 
the experimental group, the physical activity stage of participants significantly increased after the intervention; however, there was no statistical significance in the control group. A McNemar chi-square $\left(\chi^{2}\right)$ test was conducted to examine the differences in stage of change over the 12 weeks and revealed significant differences between baseline and 12 weeks $\left(\operatorname{McNemar} \chi^{2}\right.$ values $\left.=79.62, d f=7, p<0.001\right)$.

Table 3. Changes in the stage distributions of physical activity over the intervention.

\begin{tabular}{|c|c|c|c|c|c|c|}
\hline \multicolumn{7}{|c|}{ Stages of Physical Activity } \\
\hline & PC & $\mathrm{CO}$ & PR & $\mathrm{AC}$ & MA & Total $^{\mathrm{a}}$ \\
\hline \multicolumn{7}{|c|}{ Baseline-12 weeks } \\
\hline PC & $1(0)$ & $1(3)$ & $1(0)$ & $0(0)$ & $0(0)$ & $3(3)$ \\
\hline $\mathrm{CO}$ & $0(5)$ & $1(9)$ & $3(1)$ & $6(0)$ & $0(0)$ & $10(15)$ \\
\hline PR & $0(6)$ & $0(4)$ & $0(2)$ & $16(0)$ & $1(0)$ & $17(12)$ \\
\hline $\mathrm{AC}$ & $0(0)$ & $0(0)$ & $0(0)$ & $0(0)$ & $0(0)$ & $0(0)$ \\
\hline MA & $0(0)$ & $0(0)$ & $0(0)$ & $0(0)$ & $0(0)$ & $0(0)$ \\
\hline Total ${ }^{b}$ & $1(11)$ & $2(16)$ & $4(3)$ & $22(0)$ & $1(0)$ & $30(30)$ \\
\hline
\end{tabular}

Note. Parentheses are the control group. ${ }^{\text {a }}$ Frequencies indicate the sum of stage of change distribution at baseline.

${ }^{\mathrm{b}}$ Frequencies indicate the sum of stage of change distribution at 12-week time period. PC: precontemplation; CO: contemplation; PR: preparation; AC: action; MA: maintenance.

\subsection{Changes in Physical Fitness and Physical Activity}

Two-way repeated-measures ANOVA was performed to investigate the effects of the intervention on physical fitness and physical activity of participants. According to Table 4, most of physical fitness components in the experimental group significantly increased over the intervention $[F(1,58)=55.58$ for power, $p<0.001 ; F(1,58)=20.87$ for cardiovascular endurance, $p<0.001 ; F(1,58)=15.82$ for muscle strength and endurance, $p<0.01$; and $F(1,58)=12.23$ for BMI, $p<0.01$ ]. In addition, the experimental group showed significantly higher records on several physical fitness components than the control group after the intervention $[F(1,58)=50.25$ for power, $p<0.001 ; F(1,58)=20.17$ for cardiovascular endurance, $p<0.001$; and $F(1,58)=6.64$ for muscle strength and endurance, $p<0.05]$. For physical activity (METs), only participants in the experimental group showed significant increase $([F(1,58)=12.23, p<0.01)$.

Table 4. Changes in physical fitness and physical activity over the intervention.

\begin{tabular}{|c|c|c|c|c|c|c|c|}
\hline Variables & Group & $\mathbf{N}$ & $\begin{array}{l}\text { Baseline } \\
(\mathrm{M} \pm \mathrm{SD})\end{array}$ & $\begin{array}{l}\text { Week 12 } \\
(\mathrm{M} \pm \mathrm{SD})\end{array}$ & $\begin{array}{l}\text { Group } \\
F(1,58)\end{array}$ & $\begin{array}{l}\text { Time } \\
F(1,58)\end{array}$ & $\begin{array}{l}\text { Wilks } \\
\text { Lambda }(\lambda)\end{array}$ \\
\hline $\begin{array}{l}\text { Cardiovascular } \\
\text { endurance }\end{array}$ & $\begin{array}{l}\text { EG } \\
\text { CG }\end{array}$ & $\begin{array}{l}30 \\
30\end{array}$ & $\begin{array}{l}42.30 \pm 5.96 \\
39.93 \pm 5.38\end{array}$ & $\begin{array}{l}50.23 \pm 7.22 \\
41.10 \pm 5.39\end{array}$ & $20.17^{* * *}$ & $20.87^{* * *}$ & 0.33 \\
\hline Flexibility & $\begin{array}{l}\text { EG } \\
\text { CG }\end{array}$ & $\begin{array}{l}30 \\
30\end{array}$ & $\begin{array}{l}15.67 \pm 8.87 \\
15.55 \pm 8.89\end{array}$ & $\begin{array}{l}16.99 \pm 7.78 \\
16.23 \pm 8.85\end{array}$ & 0.17 & 1.59 & 0.04 \\
\hline $\begin{array}{l}\text { Muscular strength and } \\
\text { Endurance }\end{array}$ & $\begin{array}{l}\text { EG } \\
\text { CG }\end{array}$ & $\begin{array}{l}30 \\
30\end{array}$ & $\begin{array}{l}24.89 \pm 4.61 \\
23.62 \pm 2.89\end{array}$ & $\begin{array}{l}26.78 \pm 4.54 \\
24.01 \pm 2.72\end{array}$ & $6.64^{*}$ & $15.82 * *$ & 0.43 \\
\hline Power & $\begin{array}{l}\text { EG } \\
\text { CG }\end{array}$ & $\begin{array}{l}30 \\
30\end{array}$ & $\begin{array}{l}138.30 \pm 19.38 \\
132.33 \pm 13.62\end{array}$ & $\begin{array}{l}165.76 \pm 16.54 \\
134.13 \pm 13.35\end{array}$ & $50.25^{* * *}$ & $55.58^{* * *}$ & 0.51 \\
\hline Physical activity (METs) & $\begin{array}{l}\text { EG } \\
\text { CG }\end{array}$ & $\begin{array}{l}30 \\
30\end{array}$ & $\begin{array}{l}24.73 \pm 19.02 \\
24.03 \pm 15.65\end{array}$ & $\begin{array}{l}36.83 \pm 16.93 \\
26.43 \pm 15.84\end{array}$ & $7.04^{* *}$ & $12.23^{* *}$ & 0.37 \\
\hline
\end{tabular}

${ }^{*} p<0.5,{ }^{* *} p<0.01,{ }^{* * *} p<0.001$. EG: experimental group, CG: control group. BMI; body mass index. METs: metabolic equivalents.

\subsection{Changes in Psychological Variables}

Table 5 shows the result of two-way repeated-measures ANOVA to examine the effects of the intervention on psychological variables of participants. The results indicated that participants in the experimental group displayed significant increase in pros $[F(1,58)=51.47, p<0.001]$, self-efficacy $[F(1,58)=49.31, p<0.001]$, cognitive pro- 
cesses $[F(1,58)=17.17, p<0.01]$, behavioral processes $[F(1,58)=12.32, p<0.01]$, and cons $[F(1,58)=3.77, p<0.05]$ over the intervention. Additionally, participants in the experimental group showed significantly higher scores on most of psychological variables, except cons, than those in the control group after the intervention $[F(1,58)=79.45$ for self-efficacy, $p<0.001 ; F(1,58)=63.13$ for pros, $p<0.001 ; F(1,58)=29.97$ for behavioral processes, $p<0.001$; and $F(1,58)=17.17$ for cognitive processes, $p<0.01]$.

Table 5. Changes in psychological variables over the intervention.

\begin{tabular}{|c|c|c|c|c|c|c|c|}
\hline Variables & Group & $\mathbf{N}$ & $\begin{array}{l}\text { Baseline } \\
(\mathbf{M} \pm \mathbf{S D})\end{array}$ & $\begin{array}{l}\text { Week } 12 \\
(\mathrm{M} \pm \mathrm{SD})\end{array}$ & $\begin{array}{l}\text { Group } \\
F(1,58)\end{array}$ & $\begin{array}{l}\text { Time } \\
F(1,58)\end{array}$ & $\begin{array}{l}\text { Wilks } \\
\text { Lambda }(\lambda)\end{array}$ \\
\hline Pros & $\begin{array}{l}\mathrm{EG} \\
\mathrm{CG}\end{array}$ & $\begin{array}{l}30 \\
30\end{array}$ & $\begin{array}{l}2.90 \pm 0.32 \\
2.74 \pm 0.58\end{array}$ & $\begin{array}{l}3.97 \pm 0.46 \\
3.00 \pm 0.37\end{array}$ & $63.14^{* * *}$ & $51.47^{* * *}$ & 0.51 \\
\hline Cons & $\begin{array}{l}\mathrm{EG} \\
\mathrm{CG}\end{array}$ & $\begin{array}{l}30 \\
30\end{array}$ & $\begin{array}{l}2.48 \pm 0.56 \\
2.40 \pm 0.82\end{array}$ & $\begin{array}{l}1.83 \pm 0.31 \\
2.54 \pm 0.41\end{array}$ & 1.33 & 3.77 * & 0.08 \\
\hline $\begin{array}{l}\text { Self- } \\
\text { efficacy }\end{array}$ & $\begin{array}{l}\mathrm{EG} \\
\mathrm{CG}\end{array}$ & $\begin{array}{l}30 \\
30\end{array}$ & $\begin{array}{l}2.87 \pm 0.56 \\
2.56 \pm 0.72\end{array}$ & $\begin{array}{l}3.76 \pm 0.24 \\
2.23 \pm 0.37\end{array}$ & $79.45^{* * *}$ & $49.31^{* * *}$ & 0.62 \\
\hline $\begin{array}{l}\text { Cognitive } \\
\text { processes }\end{array}$ & $\begin{array}{l}\mathrm{EG} \\
\mathrm{CG}\end{array}$ & $\begin{array}{l}30 \\
30 \\
\end{array}$ & $\begin{array}{l}2.88 \pm 0.71 \\
2.81 \pm 0.90\end{array}$ & $\begin{array}{l}3.60 \pm 0.52 \\
2.87 \pm 0.41\end{array}$ & $17.17^{* *}$ & $16.60 * *$ & 0.25 \\
\hline $\begin{array}{l}\text { Behavioral } \\
\text { processes }\end{array}$ & $\begin{array}{l}\text { EG } \\
\text { CG }\end{array}$ & $\begin{array}{l}30 \\
30\end{array}$ & $\begin{array}{l}2.68 \pm 0.65 \\
2.74 \pm 0.82\end{array}$ & $\begin{array}{l}3.22 \pm 0.35 \\
2.70 \pm 0.60\end{array}$ & $29.97^{* * *}$ & $12.32 * *$ & 0.30 \\
\hline
\end{tabular}

\section{Discussion}

The current study aimed at identifying the effects of the intervention integrating Tabata exercise and psychological modification strategy on physical activity, physical fitness, and psychological variables in female adolescents. The findings indicated that the stages of physical activity of participants in the experimental group were significantly changed over the intervention, and this was supported by previous findings [33,34]. Meaningfully, all participants $(100 \%)$ in the experimental group were in the precontemplation, contemplation, and preparation stages at baseline, but $76.7 \%$ of them reported being in the action and maintenance stage over the 12-week intervention.

In addition, the findings indicated that the study participants in the experimental group also showed increases in their physical activity levels over the intervention. It might be a possible reason to be considered that the participants in this study might be willing to engage in the intervention or they satisfied to exercise with their friends because the study participants did not exercise at all or irregularly exercised before. However, such interpretation needs to be considered with caution, because this finding has been obtained from only Korean female adolescents.

The result found that the study participants' physical fitness significantly different between the experimental and control group after the 12-week intervention. In addition, physical fitness in the experimental group showed significantly increases over the intervention. These findings are supported by previous studies, demonstrating that high-intensity interval training increased cardiovascular endurance with maximal oxygen intake among female adolescents $[35,36]$. Furthermore, some studies indicated that the Tabata exercise was effective to improve muscle strength and endurance and power among female students $[35,36]$. However, the current finding revealed that there was no significant difference in flexibility between the experimental and control group over the intervention. It is plausible to explain that the Tabata protocols applied in the current study were not included an exercise to improve flexibility; instead, flexibility might have increased naturally given the nature of adolescence as a period of rapid physical development, rather than the effect of the exercise intervention.

Furthermore, the current finding indicated that the study participants as a whole experienced increases in their self-efficacy, pros, and the use of the cognitive and behavioral processes of change over the intervention, with decreases in their cons for being physically activity. This is important to document because many physical activity intervention studies 
have failed to document changes in the theoretical variables that served as the basis of the physical activity intervention in the first place [30,31]. A large number of studies widely documented that self-efficacy, cognitive and behavioral processes, and decisional balance (i.e., pros and cons) are the significant psychological determinants of physical activity in various cross-sectional studies [21,32]. Considering the lack of research on psychological strategies integrating physical activity (Tabata exercise) and psychological strategy in behavioral medicine, this study implies that the current intervention modality is a significant method to promote physical activity and positively change psychological constructs related to physical activity. Kang and Lee applied a psychological factor-based physical activity program to the physical education class of junior high school and reported that this intervention was significant to promote physical activity participation and its related competence and enjoyment [37]. More recently, Kwan and the colleagues conducted systematic review and meta-analysis to identify the effect of psychological modification strategy on improving physical activity [38]. This study concluded that the strategy is effective at increasing the time spent on physical activity and energy expenditure in physical activity, using cognitive and behavioral strategies, and improving perceived benefits and self-efficacy. In a broad viewpoint, furthermore, it needs to discuss about the associations between psychological variables and physical activity with the different people of different societies. Recent studies carried out in Malaysia and China indicated that individuals' psychological constructs such as beliefs, values, intention, and confidence play a critical role to improve health-related behaviors including physical activity and therefore the mechanism of linkage between psychological variables and a broad range of health behaviors should be understood in a socio-cultural perspective $[39,40]$.

There are a number of limitations should be considered. First, the study participants may have spent time reading other physical activity-related posts outside of the study, which we were unable to objectively assess and account for in analyses. Second, given the relatively small and homogeneous sample, findings may have limited generalizability to the diverse population. Third, although the measures used in this study were psychometrically sound, they were all self-report measures and therefore item interpretation, recall, and social desirability were not controlled for.

\section{Conclusions}

The current study is the significant attempt to employ the comprehensive approach combining physical activity and psychological strategy in female adolescents. The current study confirmed that the physical activity-related psychological intervention was feasible for improving physical and psychological health among female adolescents. Therefore, further research should continue to examine new ways to capitalize on the psychology-focused physical activity strategy and functionalities that promote physical activity involvement and its adherence for other age groups.

Author Contributions: Conceptualization, Y.K. and I.P.; formal analysis, Y.K. and I.P.; methodology, Y.K. and I.P.; writing-original draft preparation, Y.K. and I.P.; writing—review and editing, Y.K. and I.P.; funding acquisition, Y.K. All authors have read and agreed to the published version of the manuscript.

Funding: This work was supported by the Ministry of Education of the Republic of Korea and the National Research Foundation of Korea (NRF-2020S1A5A2A03041894).

Institutional Review Board Statement: The study was conducted according to the guidelines of the Declaration of Helsinki and approved by the institutional review board of Seoul National University of Science and Technology (2020-0565).

Informed Consent Statement: Informed consent was obtained from all subjects involved in the study.

Data Availability Statement: The data included in the present study are available upon request from corresponding author. 
Acknowledgments: We gratefully acknowledge all the participants for their commitment and cooperation in the process of data collection.

Conflicts of Interest: The authors declare no conflict of interest.

\section{References}

1. Yang, T.Y.; Lee, G.I. An investigation of physical activity promotion plans for female students: Action research on SPARK program based soccer class. Korean J. Sport Sci. 2020, 31, 257-274. [CrossRef]

2. U.S. Centers for Disease Control and Prevention. Adolescent and School Health, Physical Activity Facts; Centers for Disease Control and Prevention: Atlanta, GA, USA, 2017. Available online: https://www.cdc.gov/healthyyouth/data/topics/npao.htm (accessed on 1 June 2021).

3. World Health Organization. Physical Activity: Key Factors; World Health Organization: Geneva, Switzerland, 2019. Available online: https:/ / www.who.int/news-room/fact-sheets/detail/physical-activity (accessed on 2 June 2021).

4. Ministry of Health and Welfare. Survey on Adolescents' Health Behavior; Ministry of Health and Welfare: Sejong City, Korea, 2019. Available online: https:/ / www.kdca.go.kr/yhs/ (accessed on 1 June 2021).

5. Brown, W.J.; Ford, J.H.; Burton, N.W.; Marshall, A.J. Prospective study of physical activity and depressive symptoms in middle-aged women. Am. J. Med. 2005, 29, 265-272. [CrossRef] [PubMed]

6. Statistics Korea. Korean Social Trends 2017; Statistics Korea: Daejeon, Korea, 2018; pp. 101-106.

7. Kim, Y.H. Effects of lifestyle-based stage-matched intervention on adults' physical activity and its related psychological variables. Korean J. Sport Sci. 2007, 18, 62-73. [CrossRef]

8. Prochask, J.O.; DiClemente, C.C. Stage and processes of self -change of smoking: Toward and integrative model. J. Consult Clin. Psychol. 1983, 51, 390-395, 1983. [CrossRef]

9. Elezim, A.; Elezi, G.; Gontarev, S.; Georgiev, G. Application of the Transtheoretical Model (TTM) to exercise behavior among Macedonian college students. J. Hum. Sport Exerc. 2020, 15, 706-717. [CrossRef]

10. Shaver, E.R.; McGlumphy, K.C.; Gill, A.K.; Hasson, R.E. Application of the transtheoretical model to physical activity and exercise behaviors in African-American adolescents. Am. J. Health Behav. 2019, 43, 119-132. [CrossRef]

11. Ham, O.K.; Sung, K.M.; Lee, B.G.; Choi, H.W.; Im, E.O. Transtheoretical model based exercise counseling combined with music skipping rope exercise on childhood obesity. Asian Nurs. Res. 2016, 20, 116-122. [CrossRef] [PubMed]

12. Lee, H.G.; Kim, Y.H. Effects of an obesity intervention integrating physical activity and psychological strategy on BMI, physical activity, and psychological variables in male obese adolescents. Behav. Med. 2015, 41, 195-202. [CrossRef]

13. Kim, Y.H.; Kang, S.J. Effects of a weight control intervention based on the transtheoretical model on physical activity and psychological variables in middle-aged obese women. J. Women Aging 2020, 33, 556-568. [CrossRef]

14. Jeong, H.C.; Lee, E.J.; Youn, H.S.; So, W.Y. Development and implementation of a "music beeps" program to promote physical fitness in adolescents. Int. J. Environ. Res. Public Health 2020, 17, 6148. [CrossRef]

15. Yang, H.J.; Kang, J.H.; Kim, O.H.; Choi, M.; Oh, M.; Nam, J.; Sung, E. Interventions for preventing childhood obesity with smartphones and wearable device: A Protocol for a Non-Randomized Controlled Trial. Int. J. Environ. Res. Public Health 2020, 14, 184. [CrossRef]

16. Marcus, B.H.; Selby, B.C.; Niaura, V.C.; Rossi, J.S. Self-efficacy and stage of exercise behaviors change. Res. Q. Exerc. Sport 1992, 63, 60-66. [CrossRef]

17. Kim, Y.H. Adolescents' stages of change, decision balance, self-efficacy in exercise: Application of transtheoretical model. Korean J. Sport Psychol. 2002, 13, 1-19.

18. Godin, G.; Shephard, R.J. A simple method to assess exercise behavior in the community. Can. J. Appl. Sport Sci. 1985, 10, 141-146.

19. Kim, Y.H.; Cardinal, B.J.; Lee, J.Y. Understanding exercise behavior among Korean adults: A test of the transtheoretical model. Int. J. Behav. Med. 2006, 13, 295-303. [CrossRef]

20. Banville, D.; Desrosiers, P.; Genet-Volet, Y. Translating Questionnaires and Inventories Using a Cross-Cultural Translation Technique. J. Teach. Phys. Educ. 2000, 19, 374-387. [CrossRef]

21. Kim, Y.H.; Yan, J.K.; Lee, J.H. Application of self-determination theory to predicting stages of change for physical activity behavior. Korean J. Sport Sci. 2007, 18, 208-217. [CrossRef]

22. Kim, Y.H.; Kosma, M. Psychosocial and environmental correlates of physical activity among Korean older adults. Res. Aging 2013, 35, 750-767. [CrossRef]

23. Bandura, A.; Freeman, W.H.; Richard, L. Self-efficacy: The exercise of control. J. Cogn. Psychother. 1997, 13, 158. [CrossRef]

24. Kim, Y.H. Korean and American university students' exercise behavior: Application of psychological variables to predicting stages of change. Korean J. Sport Psychol. 2004, 15, 29-43.

25. Plotnikoff, R.C.; Blanchard, C.; Hotz, S.B.; Rhodes, R. Validation of the decisional balance constructs for the transtheoretical model in the exercise domain. Meas. Phys. Educ. Exerc. Sci. 2001, 5, 191-206. [CrossRef]

26. Nigg, C.R.; Norman, G.J.; Rossi, J.S.; Benisovich, S.V. Processes of exercise behavior change: Redeveloping the scale. In Proceedings of the 20th Annual Meeting of the Society of Behavioral Medicine, San Diego, CA, USA, August 1999.

27. Kim, Y.H. Application of the transtheoretical model to identify psychological constructs influencing exercise behavior: A questionnaire survey. Application of self-determination theory to predicting stages of change for physical activity behavior. Int. J. Nurs. Stud. 2007, 44, 934-944. [CrossRef] 
28. Tabata, I.; Nishimura, K.; Kouzaki, M.; Hirai, Y.; Ogita, F.; Miyachi, M.; Yamamoto, K. Effects of moderate-intensity endurance and high-intensity intermittent training on anaerobic capacity and VO2 max. Med. Sci. Sports Exerc. 1996, 28, 1327-1330. [CrossRef]

29. Cvetković, N.; Stojanović, E.; Stojiljković, N.; Nikolić, D.; Scanlan, A.T.; Milanović, Z. Exercise training in overweight and obese children: Recreational football and high-intensity interval training provide similar benefits to physical fitness. Scan. J. Med. Sci. Sports 2018, 28, 18-32. [CrossRef]

30. Domaradzki, J.; Cichy, I.; Rokita, A.; Popowczak, M. Effects of Tabata training during physical education classes on body composition, aerobic capacity, and anaerobic performance of under-, normal- and overweight adolescents. Int. J. Environ. Res. Public Health 2020, 17, 876-886. [CrossRef]

31. Kim, Y.H.; Cardinal, B.J. Effects of a transtheoretical model-based stage-matched intervention to promote physical activity among Korean adults. Int. J. Clin. Health Psychol. 2009, 9, 259-273. Available online: https://dialnet.unirioja.es/servlet/articulo?codigo=2995884 (accessed on 1 March 2021).

32. Blissmer, B.; McAuley, E. Testing the requirements on stage of physical activity among adults: The comparative effectiveness of stage-matched, mismatched, standard care, and control interventions. Ann. Behav. Med. 2002, 24, 181-189. [CrossRef]

33. An, D.J.; Kim, Y.H.; Kang, S.J. Effects of exercise information using social network service (SNS) on physical activity and psychological variables among inactive college students. Korean J. Sport Sci. 2020, 31, 189-201. [CrossRef]

34. Valle, C.G.; Tate, D.F.; Mayer, D.K.; Allicock, M.; Cai, J. A randomized trial of a Facebook-based physical activity intervention for young adults cancer survivors. J. Cancer Surviv. 2013, 7, 355-368. [CrossRef]

35. Dunn, S.L. Effects of Exercise and Dietary Intervention on Metabolic Syndrome Markers of Inactive Premenopausal Women. Ph.D. Thesis, University of New South Wales, Sydney, Australia, 2009.

36. Lim, B.G. The effects of Tabata Training Program on Physical Fitness among Male University Students. Master's Thesis, Seoul National University, Seoul, Korea, 2014.

37. Kang, H.K.; Lee, G.I. Design and implementation of physical education class for female high school students using the promotion strategies of physical activity. Korean J. Phys. Educ. 2017, 56, 287-304. [CrossRef]

38. Kwan, M.Y.W.; Dutta, P.; Bray, S.R.; Brown, D.M.Y.; Cainey, J.; Dunton, D.F.; Graham, J.D.; Robar, A.L.; Rhodes, R.E. Application of integrated approaches to understanding physical activity during the Transition to emerging adulthood. BMC Public Health 2020, 20, 426. [CrossRef]

39. Liu, K.T.; Kueh, Y.C.; Arfin, W.N.; Kim, Y.H.; Kuan, G. Application of transtheoretical model on behavioral changes, and amount of physical activity among university's students. Front. Psychol. 2019, 9, 2402. [CrossRef]

40. Qin, Z.; Song, Y.; Jin, Y. Green worship: The effects of devotional and behavioral factors on adopting electronic incense products in religious practices. Int. J. Environ. Res. Public Health 2019, 16, 3618. [CrossRef] 